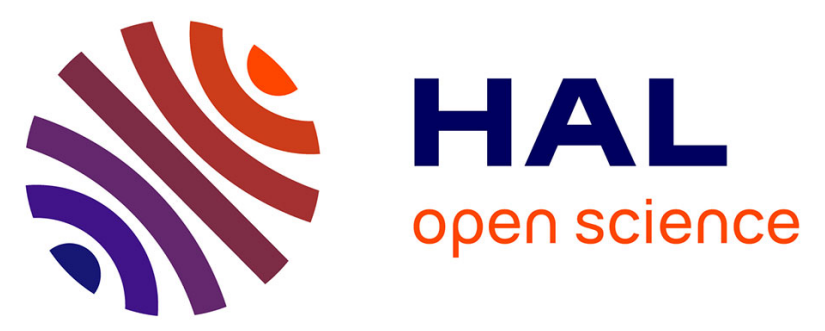

\title{
Letrozole plus GnRH analogue as preoperative and adjuvant therapy in premenopausal women with ER positive locally advanced breast cancer
}

Rosalba Torrisi, Vincenzo Bagnardi, Nicole Rotmensz, Eloise Scarano, Monica Iorfida, Paolo Veronesi, Alberto Luini, Giuseppe Viale, Armando Santoro, Marco Colleoni, et al.

\section{To cite this version:}

Rosalba Torrisi, Vincenzo Bagnardi, Nicole Rotmensz, Eloise Scarano, Monica Iorfida, et al.. Letrozole plus $\mathrm{GnRH}$ analogue as preoperative and adjuvant therapy in premenopausal women with ER positive locally advanced breast cancer. Breast Cancer Research and Treatment, 2011, 126 (2), pp.431-441. 10.1007/s10549-010-1340-y . hal-00607147

\section{HAL Id: hal-00607147 https://hal.science/hal-00607147}

Submitted on 8 Jul 2011

HAL is a multi-disciplinary open access archive for the deposit and dissemination of scientific research documents, whether they are published or not. The documents may come from teaching and research institutions in France or abroad, or from public or private research centers.
L'archive ouverte pluridisciplinaire HAL, est destinée au dépôt et à la diffusion de documents scientifiques de niveau recherche, publiés ou non, émanant des établissements d'enseignement et de recherche français ou étrangers, des laboratoires publics ou privés. 


\section{LETROZOLE PLUS GnRH ANALOGUE AS PREOPERATIVE AND ADJUVANT THERAPY IN PREMENOPAUSAL WOMEN WITH ER POSITIVE LOCALLY AVANCED BREAST CANCER.}

Rosalba Torrisi $^{\mathrm{a}, \mathrm{b}, *}$, Vincenzo Bagnardi ${ }^{\mathrm{c}, \mathrm{d}, \mathrm{e}}$, Nicole Rotmensz ${ }^{\mathrm{c}}$, Eloise Scarano ${ }^{\mathrm{a}, \mathrm{b}}$, Monica Iorfida a,b , Paolo Veronesi ${ }^{\mathrm{f}, \mathrm{h}}$, Alberto Luini ${ }^{\mathrm{f}}$, Giuseppe Viale ${ }^{\mathrm{g}, \mathrm{h}}$, Armando Santoro ${ }^{\mathrm{i}}$ Marco Colleoni ${ }^{\mathrm{a}, \mathrm{b}}$ and Aron Goldhirsch ${ }^{\mathrm{b}}$

${ }^{a}$ Research Unit of Medical Senology at the Department of Medicine, European Institute of Oncology, Milano, Italy, ${ }^{\mathrm{b}}$ Division of Epidemiology and Biostastistics, European Institute of Oncology, Milano, Italy, ${ }^{\mathrm{c}}$ Department of Statistics University of Milano Bicocca, Milano, Italy, ${ }^{\mathrm{d}}$ Frontier Science and Technology Research Foundation Southern Europe, ${ }^{\mathrm{e} D i v i s i o n}$ of Senology, European Institute of Oncology, Milano, Italy, ${ }^{\mathrm{f}}$ Division of Pathology, European Institute of Oncology, Milano ' Italy, ${ }^{\mathrm{g}}$ Medical School, University of Milano, ${ }^{\mathrm{h}}$ Dept of Oncology and Hematology, Humanitas Cancer Center, Rozzano, Italy ${ }^{i}$

Address correspondence to

Rosalba Torrisi, MD

Department of Oncology and Hematology

Humanitas Cancer Center

Via Manzoni 5620089 Rozzano, Milano, Italy

Phone: +39 02-82244502 Fax: +39 02-82244590

rosalba.torrisi@humanitas.it 


\begin{abstract}
Purpose: Patients with large ER positive tumors candidate to preoperative chemotherapy may also benefit from a concurrent endocrine intervention, but this issue has been scarcely investigated due to concerns arising from unfavorable results emerged from an adjuvant trial of concurrent tamoxifen and chemotherapy.
\end{abstract}

Patients and Methods: We retrospectively investigated the activity of letrozole plus GnRH analogue (GnRH-a) administered concurrently with preoperative chemotherapy and as adjuvant treatment in premenopausal women with locally advanced ER positive breast cancer consecutively admitted at the European Institute of Oncology. Results were compared with those of a non randomized unmatched control group of premenopausal women with locally advanced ER positive breast cancer receiving preoperative chemotherapy, followed by tamoxifen and GnRH-a after surgery.

Primary endpoints were pathological complete response (pCR) rate, decrease of Ki67 and disease free survival (DFS).

Results: One-hundred and nineteen women constituted the study group, while 95 patients served as controls. The pCR rate was $5.0 \%$ vs $1.1 \%$ in the study and control group, respectively. A statistically significant greater suppression of Ki67 was observed in patients receiving chemoendocrine therapy as compared with controls ( $\mathrm{p}=0.003)$. At a median follow up of 59 months, 26 events occurred in the chemoendocrine group and 48 in the control group. Five-yr DFS was $78 \%$ vs $41 \%$ in the study and in the control group, respectively [adjusted HR $0.4695 \%$ CI $0.27-0.79$, $\mathrm{p}=.0047]$.

Conclusions The concurrent administration of letrozole and GnRH-a with preoperative chemotherapy was highly effective in premenopausal women with large ER positive breast cancer in terms of decreased proliferation and of improved DFS. Randomized studies are warranted to establish the role of the addition of endocrine therapy to chemotherapy as standard preoperative 
approach for ER positive locally advanced breast cancer as well as of letrozole in combination with GnRH-a for the treatment of premenopauasal women with early breast cancer.

Key words: locally advanced breast cancer, ER positive breast cancer, premenopausal, preoperative treatment, letrozole and GnRH analogue 


\section{INTRODUCTION}

Administration of preoperative chemotherapy induces a pathological complete response (pCR), which represents an independent long term prognostic factor, in up to $40 \%$ of patients, depending on tumor biology [1]. However, in hormone receptor positive (HR+ve) tumors the pCR rate after preoperative chemotherapy is about 4-fold lower than in HR negative (HR-ve) tumors [1]. In the formers, the potential benefit of the addition of an endocrine intervention has been suggested but few data are available and this remains a poorly addressed issue.

Concern about the concurrent administration of tamoxifen and chemotherapy was raised by results of the SWOG INT-0100 study, which showed that the sequential admnistration of tamoxifen and chemotherapy was more effective than their concurrent administration in the adjuvant setting [2]. A large randomized study did not show any synergistic or detrimental effect of the addition of tamoxifen to a preoperative anthracyclines + taxane combination but $40 \%$ of the patients included in this study turned out to have HR-ve tumors, thus underestimating the potential benefit of concurrent endocrine manoeuvre [3].

Other randomized studies demonstrated an increased activity of chemoendocrine therapy on tumor proliferation [4,5]. However, international consensus panels currently recommend the use of preoperative endocrine therapy only in selected subsets of postmenopausal women with tumors showing high expression of hormone receptors [1].

Randomized studies have clearly shown that third generation aromatase inhibitors are superior to tamoxifen either in early and in advanced breast cancer [6].

In premenopausal women aromatase inhibitors alone may lead to an increase in gonadotropin secretion because of the reduced feedback of estrogens on hypothalamus and pituitary and a subsequent stimulation of ovarian activity [7]. On the contrary, the combination of an aromatase 
inhibitor with $\mathrm{GnRH}$ analogue $(\mathrm{GnRH}-\mathrm{a})$ may induce a complete estrogen blockade by the concomitant suppression of ovarian function and of peripheral estrogen synthesis [7]. Estrogen levels were more deeply suppressed by the combination of letrozole and triptorelin than with tamoxifen and the same GnRH-a in premenopausal women with early breast cancer [8]. However, limited experience on clinical activity of aromatase inhibitors in combination with ovarian function suppression in premenopausal women is available [9-12].

In the present study we decided to retrospectively investigate the outcome in terms of pCR rate, decrease of the tumor proliferative fraction and DFS in a consecutive series of premenopausal women who received endocrine therapy with letrozole and a GnRH-a in combination with chemotherapy as part of the preoperative treatment for locally advanced ER positive breast cancer and as adjuvant treatment for five years after surgery.

The rationale for administering letrozole was suggested by the greater activity shown in preoperative treatment of postmenopausal women with ER positive tumors in comparison with tamoxifen [13]. In addition, the combination of letrozole and ovarian suppression achieved a 50\% of instrumentally detected clinical responses, and a $3 \%$ of pCR in premenopausal women with locally advanced ER and PgR positive breast cancer [14].

Results were compared with clinical outcomes of a non randomized unmatched control group of premenopausal women who underwent surgery during the same time window in the same institution for locally advanced ER positive breast cancer, who received preoperative chemotherapy alone. As routinely recommended in premenopausal patients, control patients received tamoxifen and GnRH-a after surgery [15]. 


\section{PATIENTS AND METHODS}

\section{$\underline{\text { Patients }}$}

Since 2002 premenopausal women with histologically proven T2-T4 a-d, N0-N3 M0 ER and/or PgR positive ( $\geq 10 \%$ ) breast cancer consecutively admitted to the European Institute of Oncology (EIO) received preoperative chemotherapy and endocrine therapy with letrozole and GnRH-a within institutional protocols.

Premenopausal status was assessed by measurement of circulating estradiol at the EIO laboratory, and/or regular menses in the past 6 months in the absence of any endocrine therapy. Investigations (chest X-ray, abdomen ultrasound and bone scan or FDG-PET) were performed to exclude distant metastasis, as well as blood tests to assess normal renal, hepatic and bone marrow function.

Eligibility criteria for participation to the preoperative protocols included no previous chemotherapy/hormonotherapy, performance status 0-2 (ECOG scale), measurable or evaluable lesions, age between $18-70$ years, white blood cells $\geq 4,000 / \mathrm{mm}^{3}$, platelets $\geq 100,000 / \mathrm{mm}^{3}$, AST, ALT, LDH, gamma-GT $\leq 2.5 \mathrm{x}$ upper limit of normal and bilirubin $\leq 1.5 \mathrm{mg} / 100 \mathrm{ml}$ (unless a Gilbert syndrome was present) .

\section{$\underline{\text { Treatment }}$}

Endocrine therapy included a GnRH-a (mainly triptorelin) which was started concurrently with chemotherapy and administered either every 28 days or every 3 months thereafter.

The aromatase inhibitor letrozole $(2.5 \mathrm{mg}$ /daily) was added when circulating estradiol levels fell within a postmenopausal range, according to the EIO laboratory reference values, and was administered till surgery. Estradiol and gonadotropin levels were tested approximately at monthly intervals during preoperative treatment, in order to verify the maintenance of ovarian function suppression. 
Preoperative chemotherapy included various regimens according to preoperative clinical stage. Patients with inflammatory breast cancer received mostly the combination of epirubicin, cisplatin and infusional fluorouracil (ECF) or ECF followed by weekly paclitaxel, or dose dense AC x 4 cycles followed by docetaxel x 4 cycles, while patients with cT2-Ta-b tumors received either the combination of vinorelbine, cisplatin and infusional fluorouracil (ViFuP), or fluorouracil, vinorelbine and folinic acid (FLN), or capecitabine and oral vinorelbine, or trastuzumab + oral vinorelbine (for HER2 positive tumors). Results of these protocols have been previously published [16-19].

Patients were treated with preoperative chemotherapy given in 3-week cycles, except a small number of patients treated with the dose dense regimens. Patients were candidates to receive a maximum of 6-8 cycles.

Each patient gave a written informed consent and all protocols were notified to the Ethical Committee.

Patients not progressing during preoperative treatment continued endocrine therapy with 28-day GnRH analogue + letrozole up to 5 years.

Premenopausal patients with cT2-T4a-d N0-N3 M0 ER and/or PgR positive ( $\geq 10 \%)$ breast cancer who received preoperative chemotherapy and were submitted to surgery from 2002 and 2006 at the Division of Senology of the EIO were considered the control group. All patients were treated with chemotherapy out of the EIO internal protocols. These patients received endocrine treatment with a GnRH-a and tamoxifen administered after surgery. 


\section{$\underline{\text { Response evaluation }}$}

Responses were evaluated according to both radiological (breast ultrasound and/or mammography) and clinical evaluation, which were performed at baseline, after 3-4 cycles of chemotherapy and before surgery and were classified according to standard WHO criteria. pCR were evaluated according to Kuerer et al. criteria [20] and thus defined by the absence of invasive cancer on both the primary breast tumor and axillary lymph nodes.

In case of inflammatory breast tumors without a palpable mass, changes in clinically evaluable skin criteria (erythema, edema, peau d'orange) other than breast enlargement and tenderness were considered as response criteria.

\section{Pathology}

All patients had pathological evaluation performed at the EIO. When available, the original receptor status determinations on both the preoperative tru-cut and on the surgical specimen were considered either for the patients treated with chemotherapy and letrozole and for the control patients; otherwise only the final pathology assessment was considered. Surgical specimens were extensively sampled for the evaluation of residual tumor after primary chemotherapy, as previously reported [21].

The immunostained slides were evaluated independently by two pathologists . Only nuclear reactivity was taken into account for $\mathrm{ER}, \mathrm{PgR}$, and $\mathrm{Ki}-67$ antigen. The results were recorded as the percentage of immunoreactive cells over at least 2,000 neoplastic cells.

HER2 status was defined at immunohistochemistry (IHC) as negative (lack of membrane staining or staining of $10 \%$ or less invasive tumor cells $=0$; faint and partial staining in $>10 \%$ of 
cells $=1+$ ), and equivocal ( faint and complete staining in $>10 \%$ of cells $=2+$ ). In the latter cases fluorescence in situ hybridization (FISH) was performed to assess HER2 gene status .

\section{$\underline{\text { Statistical methods }}$}

The primary endpoints of the study were the change between pre- and post-operative values of Ki67 expression, pCR rate and DFS. Secondary endpoint was overall survival.

The Pearson $\chi^{2}$ test was used to evaluate differences in the distribution of clinical and pathological variables between study and control group.

Wilcoxon test for paired data and Wilcoxon rank sum test were used to evaluate the change from preoperative biopsy to surgical specimen in the levels of ER, PgR and Ki-67 within and between groups, respectively. McNemar test was used to evaluate the change from preoperative biopsy to surgical specimen in the HER2 overexpression.

The DFS was calculated from the date of surgery to any relapse, including ipsilateral breast recurrence, contralateral breast cancer, the appearance of a second primary cancer, or death, whichever occurred first. The OS was calculated from the date of surgery until death (from any cause). The DFS and OS functions were estimated using the Kaplan-Meier method.

The effect of chemoendocrine treatment on DFS and OS was evaluated using Cox proportional hazards regression models adjusted for prognostic clinical and pathological features and it was expressed as Hazard Ratio (HR) with 95\% confidence interval (CI).

The homogeneity of treatment effect over time was evaluated by means of a Cox models with a treatment by time (time-dependent) covariate. 
To assess whether estradiol levels decreased or increased during letrozole administration, a linear mixed models for repeated-measures was used. In the regression analysis, estradiol levels were logarithmically transformed to reduce skewness.

All analyses were carried out with the SAS software (SAS Institute, Cary, NC). All reported p-values refer to two-sided tests. 


\section{RESULTS}

Premenopausal women with histologically proven clinical T2-T4a-d N0-3 M0 ER and/or $\operatorname{PgR} \geq 10 \%$ breast cancer admitted at the Department of Medical Oncology of the EIO from January 2002 to June 2006 who received letrozole and GnRH-a preoperatively in combination with chemotherapy and as adjuvant treatment after surgery were eligible for the present study..

Patients who received letrozole only preoperatively and switched to a different endocrine agent as adjuvant treatment were excluded..

One- hundred nineteen patients were included in the final analysis. For all patients both preand post-surgical pathological tumor characteristics were available.

Premenopausal patients with ER and/or PgR positive ( $\geq 10 \%)$ breast cancer who underwent surgery at the EIO after preoperative chemotherapy during the same time window represent the control group. Patients who became amenorrhoic after chemotherapy and did not receive either GnRH a or tamoxifen after surgery were excluded .Ninety-five patients were included in the present analysis. Pre-treatment tumor biology assessment was available for two- thirds of these patients.

Table 1 summarizes baseline patient and tumor characteristics. The two groups were well balanced except for significantly younger age for the patients in the control group and a significant excess of T4 tumors in the chemoendocrine therapy group.

In addition, the two groups differed significantly in the preoperative chemotherapy regimens received, which consisted in anthracycline or anthracycline + taxane based chemotherapy in the vast majority of control patients $(93.7 \%)$ vs only $23.5 \%$ in the chemoendocrine treated patients.

Pathological complete remissions were observed in $5.0 \%$ of the chemoendocrine therapy group vs $1.1 \%$ of the control group, but the difference is not statistically significant.

Figure 1 shows the changes of ER, PgR and Ki-67 levels in each patient between preoperative biopsy and surgical specimen, according to therapy. Preoperative chemoendocrine 
therapy induced a significant decrease in the expression of both hormone receptors, while in the control group only $\mathrm{PgR}$ was significantly downregulated. A significant interaction $(\mathrm{p}=0.01)$ between treatment and changes in ER expression was observed, because ER levels were decreased in the chemoendocrine group and increased in the control group. On the other hand, Ki67 labelling index (LI) was decreased both by chemotherapy alone and by chemoendocrine therapy. However the decrease of $\mathrm{Ki} 67 \mathrm{LI}$ was significantly greater in patients receiving chemoendocrine therapy $(\Delta$ median difference: $-16 \mathrm{vs}-7, \mathrm{p}=0.003)$.

When a cut off of $<20 \%$ was considered for Ki67 LI according to our previously published data [21], a significantly higher proportion of patients in the chemoendocrine group had ki67<20\% tumors at surgery, as compared to the control group (71.4\% vs $62.1 \%$, respectively). A greater proportion of patients in the chemoendocrine group had HER2 positive tumors $(23.5 \%$ vs $11.6 \%)$. Interestingly, in the chemoendocrine group, HER2 was overexpressed in $22.8 \%$ of tumors at core biopsy and in $32.9 \%$ at surgery (McNemar p-value 0.035 ), with an overall discordance rate of $10 \%$ (95\% CI 5\%-17\%). In particular 9 patients with HER2 negative disease at baseline had overexpression of HER2 at surgery, while 2 patients who were HER2 positive at the core biopsy (one of whom received preoperative trastuzumab) did not show HER2 overexpression at surgery.

Median follow up after surgery was 59 months (range 13.2-93.6 months) Twenty-six events occurred in the chemoendocrine group vs 48 in the chemotherapy group. Five- yr DFS, was $78 \%$ in the chemotherapy + letrozole group vs $41 \%$ in the control group [HR adjusted for age, pathological size and nodal status, ER, HER2 and Ki 67 evaluated at surgery: 0.46 95\%CI 0.27-0.79 $\mathrm{p}=0047]$ (Fig 2).

A significant treatment by time interaction was observed $(\mathrm{p}=0.015)$. In fact, the advantage in DFS from chemoendocrine therapy was not observed within the first two years of observation (HR $1.12,95 \%$ CI $0.51-2.44, \mathrm{p}=0.77$ ), and became evident only afterwards (HR 0.22, 95\% CI 0.08-0.61, $\mathrm{p}=0.0035)$. 
Duration of GnRH-a was shorter in the control group than in the study group: in fact, the proportion of patients discontinuing GnRH-a at 4 years after surgery were $12 \%$ and $4 \%$, respectively (Wilcoxon $\mathrm{p}$-value, evaluating differences in time to discontinuation, 0.049). Moreover, a significantly greater proportion of patients receiving tamoxifen discontinued GnRH-a in the last 3 years, as compared with those receiving adjuvant letrozole $(24.7 \%$ vs $8.6 \%$, respectively). However, time to discontinuation was not significantly associated with the risk of relapse when evaluated in a time-dependent Cox regression model:

Thirteen $(11 \%)$ deaths in the GnRH analogue + letrozole group vs $17(18 \%)$ deaths in the control group were observed. Five-yr overall survival was $89 \%$ vs $81 \%$ in the chemotherapy + letrozole and in the control groups, respectively [HR, adjusted for adjusted for age, pathological size and nodal status, ER, HER2 and Ki 67 evaluated at surgery, 0.85 95\%CI 0.37-1.94, p=0.71].

The analysis of the extent of ovarian suppression after the addition of letrozole to GnRH-a during preoperative treatment was performed. Circulating estradiol levels after administration of GnRH-a were available for 111 patients. Ninety-eight patients had estradiol assessment after 1month and 73 after 2-month letrozole treatment.. Estradiol levels were significantly suppressed (p $<0.001$ ) by the addition of letrozole (Figure 3). However, changes of estradiol levels were not associated with clinical and pathological response nor with type of chemotherapy (anthracyclineand/or taxane based vs other) (data not shown). 


\section{DISCUSSION}

It is generally accepted that ER status is one of the most powerful predictors of pCR after preoperative chemotherapy in multivariate analyses [1,21]. Locally advanced ER positive tumors respond only partially to preoperative chemotherapy and the rate of pCR in ER positive HER2 negative tumors is significantly lower as compared with those obtained in triple negative and HER2 positive tumors [22-25].

Despite the likelihood of achieving a pCR is almost negligible, long term outcome is consistently better in the former cohort of patients [22.25]. The impact of subsequent adjuvant endocrine treatment is generally pointed out to partly explain this outcome.

However the addition of endocrine therapy in the preoperative setting has generally been poorly endorsed and rarely pursued mainly due to the concern raised by the results of the SWOG study showing that patients receiving concurrent chemotherapy and tamoxifen fared worse than those receiving the sequential administration of these two therapies [2].

In the present study we investigated the effect on short and long term outcome of the addition of endocrine therapy as part of the preoperative treatment in a cohort of premenopausal women with large ER positive tumors.

We demonstrated a substantial clinical activity for the combination of chemotherapy and letrozole and GnRH-a either in terms of response to preoperative treatment (pCR rate, decrease of Ki67 LI) and of long term outcome (DFS).

The chemotherapy + letrozole group performed significantly better than the control group both in terms of decrease in tumor Ki67 LI, which is an independent prognostic factor of long term outcome, and in terms of DFS, with a 54\% reduction of the relative risk of a new event. In addition, the pCR rate was higher in the chemoendocrine group as compared to the chemotherapy alone one (5.0\% vs $1.1 \%$, respectively) but the difference was not statistically significant. The pCR rate 
observed in the chemoendocrine group was within the range reported in the literature for this tumor population, although less than one third of patients received anthracycline based chemotherapy and only a marginal proportion received taxanes [1].

The issue of the concurrent administration of chemotherapy and endocrine therapy in the preoperative setting has been poorly addressed. The GEPARDO study randomized 250 women with locally advanced breast cancer to receive 4 cycles of dose dense doxorubicin + paclitaxel with or without tamoxifen [3]. Patients were not selected for the tumor HR status. A pCR rate of about 10\% was observed in both groups. In a subset analysis of the study, including 196 patients with available centrally reviewed core biopsies, about $40 \%$ of tumors turned out to be ER negative [26]. Patients with ER positive tumors treated with the combination of chemotherapy and tamoxifen had no pCR while $3.5 \%$ of pCR was observed in the same subset of tumors treated with chemotherapy alone. However, the pCR rate in ER negative tumors was similar in the 2 groups, suggesting that the lack of benefit of additional tamoxifen was not attributable to a detrimental effect of the concomitant administration of the endocrine agent [26].

Further studies showed a positive effect in decreasing tumor proliferative fraction by the addition of an hormonal agent to chemotherapy, in postmenopausal women, although clinical response rates were similar $[4,5]$.

In premenopausal women limited evidence of activity of aromatase inhibitors is available, although aromatase inhibitors are routinely used in clinical practice after tamoxifen failure.

The combination of anastrozole and GnRH-a showed a significant activity in premenopausal patients either as $1^{\text {st }}$ line treatment for metastatic disease or upon progression on tamoxifen $[9,12]$. More recently, $1^{\text {st }}$ line treatment of premenopausal women with letrozole combined with GnRH-a showed comparable efficacy to that of letrozole in postmenopausal women with HR +ve metastatic breast cancer [11].

To our knowledge, this is the first report showing substantial activity of letrozole in premenopausal patients with early breast cancer either preoperatively and in the adjuvant setting. 
A number of considerations should be made while interpreting these results. First of all, we should recognize the retrospective design of the study and the choice of a non randomized unmatched control group.

In addition, comparative results may be affected by the poor outcome of the control group, although 95\% of these patients received an anthracycline/taxane based preoperative chemotherapy and about $30 \%$ received additional adjuvant chemotherapy, and by the lower proportion of T4 and HER2 positive tumors included in this group.

Moreover, the dramatically increased risk of relapse observed in these patients after the first 2 years is not easy to be explained. We speculated that it could be attributable to a different duration of GnRH-a treatment. The earlier discontinuation of GnRH-a after 2 years intriguingly mirrored the increased risk of relapse observed thereafter in the control patients. However, statistical analysis did not confirm a correlation between $\mathrm{GnRH}-\mathrm{a}$ duration and risk of relapse, albeit the relative small number of patients cannot allow us to draw definitive conclusions on the role of ovarian suppression duration on clinical outcomes.

On the other hand, the present results may speculatively suggest that anticipating ovarian suppression may represent a valuable approach to improve the outcome of premenopausal patients with ER positive tumors.

Conversely, results obtained in the chemoendocrine study group are comparable with literature data in terms of 5-yr DFS, although stratified information about the clinical outcome according to menopausal status is not generally reported in trials of preoperative therapy.

The GeparDUO study reported a pCR of $1.8 \%$ but a 3-yr DFS of $90 \%$ in a subgroup of 56 patients with ER + ve and HER2 negative tumors receiving dose dense vs standard anthracycline + taxane based chemotherapy [27]. 
Guarneri et al reported a pCR rate of $8 \%$ and a 5-yr progression free survival of about $60-66 \%$ in more than one thousand women with locally advanced HR+ve breast cancer treated with preoperative chemotherapy and the addition of endocrine therapy only after surgery, but both pre and postmenopausal patients were included [22].

We should be aware that results reported herein derive from non randomized comparisons and that the favourable results observed in the chemoendocrine series may be biased by the inclusion of patients who had not progressed on preoperative letrozole + ovarian suppression treatment, being thus more likely to benefit of the same combination in the adjuvant setting.

The results of our study are also hardly comparable with those of the ABCSG 12 trial, a large randomized study comparing through a $2 \times 2$ factorial design 3 -yr treatment with anastrozole or tamoxifen, both in combination with goserelin, with or without zoledronic acid (twice per year) in 1810 premenopausal women with $\mathrm{HR}+\mathrm{ve}$ breast cancer [10]. After a median follow up of 48 months DFS was about $90 \%$ in both endocrine arms alone [10]. However the study population was entirely different, since in the Austrian study about $75 \%$ of the patients had $2 \mathrm{~cm}$ or less tumors and only $30 \%$ of the patients had positive nodes at surgery, while in the present study all patients had by inclusion criteria $>2 \mathrm{~cm}$ tumors at diagnosis and $20 \%$ of them had T4 tumors.

Despite the marginal number of pCRs, women with ER+ve tumors experience a significant advantage in DFS, as compared with women with ER-ve tumors, which is consistent across all previous studies $[22,25,27]$. It may thus be speculated that factors other than pCR rate may be relevant for predicting long term outcome after preoperative treatment in the former group. Ellis and colleagues showed that post-treatment proliferation combined with the amount of residual tumor in the axilla and in the breast, considered as continuous variables, constitute a powerful prognostic index in postmenopausal women with $\mathrm{HR}+\mathrm{ve}$ breast cancer treated preoperatively with 
letrozole or anastrozole [28]. We have previously reported that Ki67 LI represents an independent prognostic factor of long term outcome also in patients receiving preoperative chemotherapy [29]

In our study we observed a significantly greater decrease of Ki67 LI in the group of patients receiving chemotherapy and endocrine therapy as compared to those receiving chemotherapy alone. According to our results, the concern regarding the concomitant administration of chemotherapy and endocrine therapy should be banished Although our results derive from a non randomized comparison, the absolute decrease of Ki67 LI obtained with the chemoendocrine combination should relieve concerns about the possible negative effect of endocrine manoeuvre concurrent with chemotherapy. In addition, whatever is the reason of the poor outcomes observed in the conventional therapy arm, DFS results reported herein in patients receiving letrozole and GnHR-a are encouraging and do not point out a potential detrimental effect.

We observed an overall discordance rate of $10 \%$ in HER2 expression between core biopsy and surgical specimens. Possible explanations for this findings include tumor heterogeneity, limited tumor sampling of the core biopsy but also a change in HER2 expression as a possible effect of preoperative treatments. Nevertheless, the determination of tumor features in surgical specimens after preoperative treatment is warranted.

We confirmed that the addition of letrozole induced a further suppression of estradiol levels as compared to GnRH-a alone, which was independent from the variable potential gonadotoxicity of chemotherapy different regimens. Most women achieved estradiol levels below the detectable lower limit of the reference laboratory $(5 \mathrm{pg} / \mathrm{mL})$, while in a recently published evaluation of the combination of GnRH-a with anastrozole in premenopausal women with advanced breast cancer the mean lowest level of estradiol was about $15 \mathrm{pg} / \mathrm{mL}$ [12]. These results suggest that letrozole is able to induce a greater estrogen suppression in premenopausal women, as previously demonstrated in 
postmenopausal women [30]. In this view, obtaining a complete endocrine suppression could be even more clinically relevant in premenopausal than in postmenopausal women.

In conclusion, we demonstrated that endocrine therapy administered concurrently with preoperative chemotherapy in premenopausal women with locally advanced ER positive tumors is not detrimental in terms of pCR and may on the contrary potentally improve the decrease of either tumor proliferation and the risk of relapse. Letrozole in combination with $\mathrm{GnRH}-\mathrm{a}$ in premenopausal women is active and may represent a safe option even in the adjuvant treatment, although results from randomized trials and long term safety data are needed before this treatment could become a standard, when tamoxifen is contraindicated . Randomized studies are also warranted to better establish the role of endocrine therapy as part of the preoperative treatment of large ER positive breast cancer. 
ACKNOWLEDGEMENTS

The Authors are indebted to Novartis FARMA S.p.A. for the help in the revision of English format 
CONFLICT OF INTEREST

The Authors declare they have no conflict of interest 


\section{REFERENCES}

1. Kaufmann M, von Minckwitz G, Bear HD, Buzdar A, McGale P, Bonnefoi H, Colleoni M, Denkert C, Eiermann W, Jackesz R, Makris A, Miller W, Pierga JY, Semiglazov V, Schneeweiss A, Souchon R, Stearns V, Untch M, Loibl S. Recommendations from an international expert panel on the use of neoadjuvant (primary) systemic treatment of operable breast cancer: new perspectives 2006. Ann Oncol. 2007, 18:1927-1934.

2. Albain KS, Barlow WE, Ravdin PM, Farrar WB, Burton GV, Ketchel SJ, Cobau CD, Levine EG, Ingle JN, Pritchard KI, Lichter AS, Schneider DJ, Abeloff MD, Henderson IC, Muss HB, Green SJ, Lew D, Livingston RB, Martino S, Osborne CK; Breast Cancer Intergroup of North America. Adjuvant chemotherapy and timing of tamoxifen in postmenopausal patients with endocrine-responsive, node-positive breast cancer: a phase 3 , open-label, randomised controlled trial. Lancet. 2009, 374:2055-2063.

3. Von Minckwitz G, Costa SD, Raab G, Blohmer JU, Eidtmann H, Hilfrich J, Merkle E, Jackisch C, Gademann G, Tulusan AH, Eiermann W, Graf E and Kaufmann M (2001) Dose-dense doxorubicin, docetaxel and granulocyte colony-stimulating factor support with or without tamoxifen as preoperative therapy in patients with operable carcinoma of the breast: a randomized, controlled open phase IIb study. J Clin Oncol 19: 3506-3515.

4. Bottini A, Berruti A, Brizzi MP, Bersiga A, Generali D, Allevi G, Aguggini S, Bolsi G, Bonardi S, Tondelli B, Vana F, Tampellini M, Alquati P, Dogliotti L (2005) Cytotoxic and antiproliferative activity of the single agent epirubicin versus epirubicin plus tamoxifen as primary chemotherapy in human breast cancer: a single-institution phase III trial. Endocrine Related Cancer 12: 383-392.

5. Bottini A, Generali D, Brizzi MP, Fox SB, Bersiga A, Bonardi S, Allevi G, Aguggini S, Bodini G, Milani M, Dionisio R, Bernardi C, Montruccoli A, Bruzzi P, Harris AL, Dogliotti L, Berruti A. (2006) Randomized phase II trial of letrozole and letrozole plus low-dose metronomic oral cyclophosphamide as primary systemic treatment in elderly breast cancer patients. J Clin Oncol 24: 3623-3628.

6. Winer EP, Hudis C, Burstein HJ, Wolff AC, Pritchard KI, Ingle JN, Chlebowski RT, Gelber R, Edge SB, Gralow J, Cobleigh MA, Mamounas EP, Goldstein LJ, Whelan TJ, Powles TJ, Bryant J, Perkins C, Perotti J, Braun S, Langer AS, Browman GP, Somerfield MR (2005) .American Society of Clinical Oncology technology assessment on the use of aromatase inhibitors as adjuvant therapy for postmenopausal women with hormone receptor-positive breast cancer: status report 2004.J Clin Oncol. 23:619-629.

7. Smith IE and Dowsett M (2003). Aromatase inhibitors in breast cancer. N Engl J Med 348: 2431-2442.

8. Rossi E, Morabito A, De Maio E, Di Rella F, Esposito G, Gravina A, Labonia V, Landi G, Nuzzo F, Pacilio C, Piccirillo MC, D'Aiuto G, D'Aiuto M, Rinaldo M, Botti G, Gallo C, Perrone F, de Matteis A (2008) Endocrine effects of adjuvant letrozole + triptorelin compared with tamoxifen + triptorelin in premenopausal patients with early breast cancer.J Clin Oncol 26:264-270. 
9. Forward DP, Cheung KL, Jackson L, Robertson JF (2004). Clinical and endocrine data for goserelin plus anastrozole as second-line endocrine therapy for premenopausal advanced breast cancer. Br J Cancer 90: 590-594.

10. Gnant M, Mlineritsch B, Schippinger W, Luschin-Ebengreuth G, Pöstlberger S, Menzel C, Jakesz R, Seifert M, Hubalek M, Bjelic-Radisic V, Samonigg H, Tausch C, Eidtmann H, Steger G, Kwasny W, Dubsky P, Fridrik M, Fitzal F, Stierer M, Rücklinger E, Greil R; al.Endocrine therapy plus zoledronic acid in premenopausal breast cancer (2009). N Engl J Med. 360:679-691. Erratum in: N Engl J Med. 2009 May 28;360(22):2379.

11. Park IH, Ro J, Lee KS, Kim EA, Kwon Y, Nam BH, Jung SY, Lee S, Kim SW, Kang HS Phase II Parallel Group Study Showing Comparable Efficacy Between Premenopausal Metastatic Breast Cancer Patients Treated With Letrozole Plus Goserelin and Postmenopausal Patients Treated With Letrozole Alone As First-Line Hormone Therapy (2010). J Clin Oncol $28: 2705-11$ Apr 26 Epub ahead of print

12. Carlson RW, Theriault R, Schurman CM, Rivera E, Chung CT, Phan S, Rice EK, Arun B, Dice K, Chiv D, Greene M, Valero V (2010). Phase II trial of anastrozole plus Goserelin in the treatment of hormone receptor positive metastatic carcinoma of the breast in premenopausal women. J Clin Oncol 28: 3917-3921

13. Eiermann W, Paepke S, Appfelstaedt J, Llombart-Cussac A, Eremin J, Vinholes J, Mauriac L, Ellis M, Lassus M, Chaudri-Ross HA, Dugan M, Borgs M (2001) Preoperative treatment of postmenopausal breast cancer patients with letrozole: A randomized double-blind multicenter study. Ann Oncol 12: 1527-1532

14. Torrisi R, Bagnardi V, Pruneri G, Ghisini R, Bottiglieri L, Magni E, Veronesi P, D'Alessandro C, Luini A, Dellapasqua S, Viale G, Goldhirsch A, Colleoni M.(2007) Antitumor and biological effects of letrozole and GnRH analogue as primary therapy in premenopausal women with ER and PgR positive locally advanced operable breast cancer . Br J Cancer 97: 802-808.

15. LHRH-agonists in Early Breast Cancer Overview group, Cuzick J, Ambroisine L, Davidson N, Jakesz R, Kaufmann M, Regan M, Sainsbury R. (2007) Use of luteinising-hormonereleasing hormone agonists as adjuvant treatment in premenopausal patients with hormonereceptor-positive breast cancer: a meta-analysis of individual patient data from randomised adjuvant trials. Lancet. 369:1711-23.

16. D'Alessandro C, Dellapasqua S, Orlando L, Santoro L, Maisonneuve P, Torrisi R, Balduzzi A, Scarano E, Ghisini R, Peruzzotti G, Goldhirsch A, Colleoni M. (2008). Role of endocrine responsiveness and HER2/neu overexpression in inflammatory breast cancer treated with multimodality preoperative therapy. Breast J. 14:435-41.

17. Torrisi R, Dellapasqua S, Ghisini R, Santoro L, Maisonneuve P, Torrisi R, Balduzzi A, Scarano E, Ghisini R, Peruzzotti G, Goldhirsch A, Colleoni M (2008) Preoperative concurrent chemo- and endocrine therapies for women with large operable breast cancer expressing steroid hormone receptors. The Breast. 17:654-660.

18. Torrisi R, Orlando L, Ghisini R, Viale G, Veronesi P, Luini A, Intra M, Peruzzotti G, Rocca A, Balduzzi A, Cardillo A, Goldhirsch A, Colleoni M.(2007) A phase II study of primary 
dose-dense sequential doxorubicin plus cyclophosphamide and docetaxel in cT4 breast cancer. Anticancer Res. 26:3861-3864.

19. Iorfida M, Bagnardi V, Balduzzi A Dellapasqua S, Cardillo A, Luini A, Intra M, Minchella I, Veronesi P, Viale G, Goldhirsch A, Colleoni M. (2010) Preoperative therapy with trastuzumab and oral vinorelbine (+/- endocrine therapy) in patients with HER2-positive breast cancer. The Breast. 19:128-132.

20. Kuerer HM, Newman LA, Smith TM, Ames FC, Hunt KK, Dhingra K, Theriault RL, Singh G, Binkley SM, Sneige N, Bucholz TA, Ross MI, McNeese MD, Buzdar AU, Hortobagyi GN, Singletary SE. (1999) Clinical course of breast cancer patients with complete pathologic primary tumor and axillary lymph node response to doxorubicin-based neoadjuvant chemotherapy. J Clin Oncol 17 : 460-469.

21. Colleoni M, Viale G, Zahrieh D, Pruneri G, Gentilini O, Veronesi P, Gelber RD, Curigliano G, Torrisi R, Luini A, Intra M, Galimberti V, Renne G, Nolè F, Peruzzotti G, and Goldhirsch A (2004). Chemotherapy is more effective in patients with breast cancer not expressing steroid hormone receptors: a study of preoperative treatment. Clin Cancer Res 10: 6622-6628.

22. Guarneri V, Broglio K, Kau SW, Cristofanilli M, Buzdar AU, Valero V, Buchholz T, Meric F, Middleton L, Hortobagyi GN, Gonzalez-AnguloAM. (2006) Prognostic value of pathologic complete response after primary chemotherapy in relation to hormone receptor status and other factors. J Clin Oncol. 24:1037-1044.

23. Gianni L, Baselga J, Eiermann W, Guillem Porta V, Semiglazov V, Lluch A, Zambetti M, Sabadell D, Raab G, Llombart Cussac A, Bozhok A, Martinez-Agulló A, Greco M, Byakhov M, Lopez Lopez JJ, Mansutti M, Valagussa P, Bonadonna G; European Cooperative Trial in Operable Breast Cancer Study Group (2005) Feasibility Feasibility and tolerability of sequential doxorubicin/paclitaxel followed by cyclophosphamide, methotrexate, and fluorouracil and its effects on tumor response as preoperative therapy. Clin Cancer Res. 11:8715-21.

24. Gianni L, Eiermann W, Semiglazov V, Manikhas A, Lluch A, Tjulandin S, Zambetti M, Vazquez F, Byakhow M, Lichinitser M, Climent MA, Ciruelos E, Ojeda B, Mansutti M, Bozhok A, Baronio R, Feyereislova A, Barton C, Valagussa P, Baselga J (2010) .

Neoadjuvant chemotherapy with trastuzumab followed by adjuvant trastuzumab versus neoadjuvant chemotherapy alone, in patients with HER2-positive locally advanced breast cancer (the NOAH trial): a randomised controlled superiority trial with a parallel HER2negative cohort. Lancet. 375:377-84.

25. Colleoni M, Viale G, Zahrieh D, Bottiglieri L, Gelber RD, Veronesi P, Balduzzi A, Torrisi R, Luini A, Intra M, Dellapasqua S, Cardillo A, Ghisini R, Peruzzotti G, Goldhirsch A (2008) .Expression of ER, PgR, HER1, HER2, and response: a study of preoperative chemotherapy. Ann Oncol. 19:465-472. 
26. von Minckwitz G, Sinn HP, Raab G, Loibl S, Blohmer JU, Eidtmann H, Hilfrich J, Merkle E, Jackisch C, Costa SD, Caputo A, Kaufmann M; German Breast Group (2008). Clinical response after two cycles compared to HER2, Ki-67, p53, and bcl-2 in independently predicting a pathological complete response after preoperative chemotherapy in patients with operable carcinoma of the breast. Breast Cancer Res 10(2):R30. Epub 2008 Apr 1.

27. Darb-Esfahani S, Loibl S, Müller BM, Roller M, Denkert C, Komor M, Schlüns K, Blohmer JU, Budczies J, Gerber B, Noske A, du Bois A, Weichert W, Jackisch C, Dietel M, Richter K, Kaufmann M, von Minckwitz G (2009).Identification of biology-based breast cancer types with distinct predictive and prognostic features: role of steroid hormone and HER2 receptor expression in patients treated with neoadjuvant anthracycline/taxane-based chemotherapy.Breast Cancer Res. 11(5):R69. Epub .

28. Ellis MJ, Tao Y, Luo J, Evans DB, Bhatnagar AS, Chaudri Ross HA, von Kameke A, Miller WR, Smith I, Eiermann W, Dowsett M. (2008) Outcome prediction for estrogen receptorpositive breast cancer based on postneoadjuvant endocrine therapy tumor characteristics. $\mathbf{J}$ Natl Cancer Inst. 100:1380-1388.

29. Colleoni M, Bagnardi V, Rotmensz N, Dellapasqua S, Viale G, Pruneri G, Veronesi P, Torrisi R, Luini A, Intra M, Galimberti V, Montagna E, Goldhirsch A (2009) A risk score to predict disease-free survival in patients not achieving a pathological complete remission after preoperative chemotherapy for breast cancer". Ann Oncol 20: 1178-1184.

30. Geisler J, Elle H, Ekse D, Duong NK, Evans DB, Nordbø Y, Aas T, Lønning PE (2008) Letrozole is superior to anastrozole in suppressing breast cancer tissue and plasma estrogen levels. Cin Cancer Res 14:6330-6335. 
Table 1. Patient and tumor characteristics at time of diagnosis of primary breast cancer and primary chemotherapy regimen received by study group.

\begin{tabular}{|c|c|c|c|}
\hline & $\begin{array}{c}\text { CT+Letrozole } \\
(\mathrm{n}=119) \\
\text { No. }(\%)\end{array}$ & $\begin{array}{c}\text { CT } \\
(\mathrm{n}=95) \\
\text { No. }(\%)\end{array}$ & $\mathrm{p}^{*}$ \\
\hline $\begin{array}{l}\text { Year of diagnosis } \\
2002-2003 \\
2004-2006\end{array}$ & $\begin{array}{l}29(24.4) \\
90(75.6)\end{array}$ & $\begin{array}{l}42(44.2) \\
53(55.8)\end{array}$ & 0.0022 \\
\hline $\begin{array}{l}\text { Age (years) } \\
<35 \\
35-49\end{array}$ & $\begin{array}{c}14(11.8) \\
105(88.2)\end{array}$ & $\begin{array}{l}26(27.4) \\
69(72.6)\end{array}$ & 0.0036 \\
\hline $\begin{array}{l}\text { Histotype } \\
\text { ductal } \\
\text { lobular } \\
\text { others }\end{array}$ & $\begin{array}{c}150(76.1) \\
29(14.7) \\
18(9.1)\end{array}$ & $\begin{aligned} 72 & (87.8) \\
0 & (0.0) \\
10 & (12.2)\end{aligned}$ & 0.49 \\
\hline $\begin{array}{l}\text { Grade } \\
1-2 \\
3 \\
\text { Unknown }\end{array}$ & $\begin{array}{c}82(68.9) \\
32(26.9) \\
5(4.2)\end{array}$ & $\begin{array}{l}31(32.6) \\
15(15.8) \\
49(51.6)\end{array}$ & 0.57 \\
\hline $\begin{array}{l}\text { Clinical T } \\
2 \\
3 \\
4\end{array}$ & $\begin{array}{l}65(54.6) \\
29(24.4) \\
25(21.0)\end{array}$ & $\begin{array}{c}58(61.1) \\
29(30.5) \\
8(8.4)\end{array}$ & 0.038 \\
\hline $\begin{array}{l}\text { Clinical N } \\
\text { Positive } \\
\text { Negative } \\
\text { X } \\
\text { unknown }\end{array}$ & $\begin{aligned} 78 & (65.5) \\
35 & (29.4) \\
2 & (1.7) \\
4 & (3.4)\end{aligned}$ & $\begin{array}{c}71(74.7) \\
20(21.1) \\
1(1.1) \\
3(3.2)\end{array}$ & 0.33 \\
\hline $\begin{array}{l}\text { ER/PgR } \\
\text { ER or PgR } 1-49 \% \\
\text { ER and } P g R \geq 50 \% \\
\text { unknown }\end{array}$ & $\begin{array}{c}77(64.7) \\
42(35.3) \\
0(0.0)\end{array}$ & $\begin{array}{l}35(36.8) \\
27(28.4) \\
33(34.7)\end{array}$ & 0.28 \\
\hline $\begin{array}{l}\text { Her } 2 / \text { neu status } \\
\text { negative } \\
\text { positive }(3+) \\
\text { unknown }\end{array}$ & $\begin{array}{c}97(81.5) \\
22(18.5) \\
0(0.0)\end{array}$ & $\begin{aligned} 51 & (53.7) \\
4 & (4.2) \\
40 & (42.1)\end{aligned}$ & 0.053 \\
\hline $\begin{array}{l}\text { Ki-67 } \\
<20 \% \\
\geq 20 \% \\
\text { unknown }\end{array}$ & $\begin{array}{c}28(23.5) \\
90(75.6) \\
1(0.8)\end{array}$ & $\begin{array}{l}19(20.0) \\
36(37.9) \\
40(42.1)\end{array}$ & 0.14 \\
\hline $\begin{array}{l}\text { Primary CT regimen } \\
\text { antracyclines } \\
\text { antracyclines and taxanes } \\
\text { others }\end{array}$ & $\begin{array}{c}18(15.1) \\
10(8.4) \\
91(76.5)\end{array}$ & $\begin{array}{c}40(42.1) \\
49(51.6) \\
6(6.3)\end{array}$ & $<0.0001$ \\
\hline Additional trastuzumab & $14(11.8)$ & $3(3.2)$ & \\
\hline $\begin{array}{l}\text { Response to primary therapy } \\
\text { pCR } \\
\text { partial response } \\
\text { stable disease } \\
\text { Others }\end{array}$ & $\begin{array}{c}6(5.0) \\
62(52.1) \\
51(42.9)\end{array}$ & $\begin{array}{c}1(1.1) \\
41(43.2) \\
53(55.8)\end{array}$ & 0.10 \\
\hline
\end{tabular}

Abbreviations: $\mathrm{ER}=$ estrogen receptor; $\mathrm{PgR}=$ progesterone receptor; $\mathrm{CT}=$ chemotherapy; $\mathrm{pCR}=$ pathological complete response.

$* \chi^{2}$ test comparing frequencies between CT+Letrozole group and CT group. Unknown were not considered in the pvalue calculation 
Table 2. Patient and tumor characteristics at time of surgery and adjuvant therapy, by study group.

\begin{tabular}{|c|c|c|c|}
\hline & $\begin{array}{c}\text { CT+Letrozole } \\
(\mathrm{n}=119) \\
\text { No. }(\%)\end{array}$ & $\begin{array}{c}\text { CT } \\
(n=95) \\
\text { No. }(\%)\end{array}$ & $\mathrm{p}^{*}$ \\
\hline $\mathrm{pT}$ & & & 0.45 \\
\hline pT0, in situ & $8(6.7)$ & $1(1.1)$ & \\
\hline pT1 & $38(31.9)$ & $31(32.6)$ & \\
\hline pT2 & $45(37.8)$ & $37(38.9)$ & \\
\hline pT3 & $21(17.6)$ & $21(22.1)$ & \\
\hline pT4 & $1(0.8)$ & $1(1.1)$ & \\
\hline pTX & $6(5.0)$ & $4(4.2)$ & \\
\hline Positive lymph nodes (No.) & & & 0.20 \\
\hline None & $32(26.9)$ & $18(18.9)$ & \\
\hline $1-3$ & $43(36.1)$ & $31(32.6)$ & \\
\hline$\geq 4$ & $44(37.0)$ & $46(48.4)$ & \\
\hline ER & & & 0.34 \\
\hline 0 & $2(1.7)$ & $0(0.0)$ & \\
\hline $1-49 \%$ & $14(11.8)$ & $9(9.5)$ & \\
\hline$\geq 50 \%$ & $97(81.5)$ & $85(89.5)$ & \\
\hline Unknown & $6(5.0)$ & $1(1.1)$ & \\
\hline Her2/neu status & & & 0.17 \\
\hline Negative & $85(71.4)$ & $83(87.4)$ & \\
\hline Positive (3+) & $28(23.5)$ & $11(11.6)$ & \\
\hline Unknown & $6(5.0)$ & $1(1.1)$ & \\
\hline Ki-67 & & & 0.040 \\
\hline$<20 \%$ & $85(71.4)$ & $59(62.1)$ & \\
\hline$\geq 20 \%$ & $25(21.0)$ & $33(34.7)$ & \\
\hline Unknown & $9(7.6)$ & $3(3.2)$ & \\
\hline Surgical treatment & & & 0.91 \\
\hline Total mastectomy & $63(52.9)$ & $51(53.7)$ & \\
\hline Breast conservation & $56(47.1)$ & $44(46.3)$ & \\
\hline Radiotherapy & & & 0.12 \\
\hline No & $27(22.7)$ & $28(29.5)$ & \\
\hline Yes & $92(77.3)$ & $67(70.5)$ & \\
\hline Adjuvant CT & & & 0.0002 \\
\hline No & 109 (91.6) & $69(72.6)$ & \\
\hline Yes & $10(8.4)$ & $26(27.4)$ & \\
\hline Adjuvant Trastuzumab & & & 0.0023 \\
\hline No & $105(88.2)$ & $94(98.9)$ & \\
\hline Yes & $14(11.8)$ & $1(1.1)$ & \\
\hline
\end{tabular}

Abbreviations: $\mathrm{ER}=$ estrogen receptor; $\mathrm{CT}=$ chemotherapy.

$* \chi^{2}$ test comparing frequencies between $\mathrm{CT}+$ Letrozole group and CT group. Unknown were not considered in the pvalue calculation 
Figure 1. Matched box plots showing changes of ER, PgR and Ki-67 levels in each patient between preoperative biopsy and surgical specimen, by study group. Patients achieving pathological complete response were not considered. Half boxes represent the interquartile range and the horizontal bold lines across the boxes indicates the median. Whiskers (standard span) were extended to $1.5 \times$ the interquartile range. Arithmetic means are indicated with + symbol. $\mathrm{P}$-values are based on the Wilcoxon test for paired data.

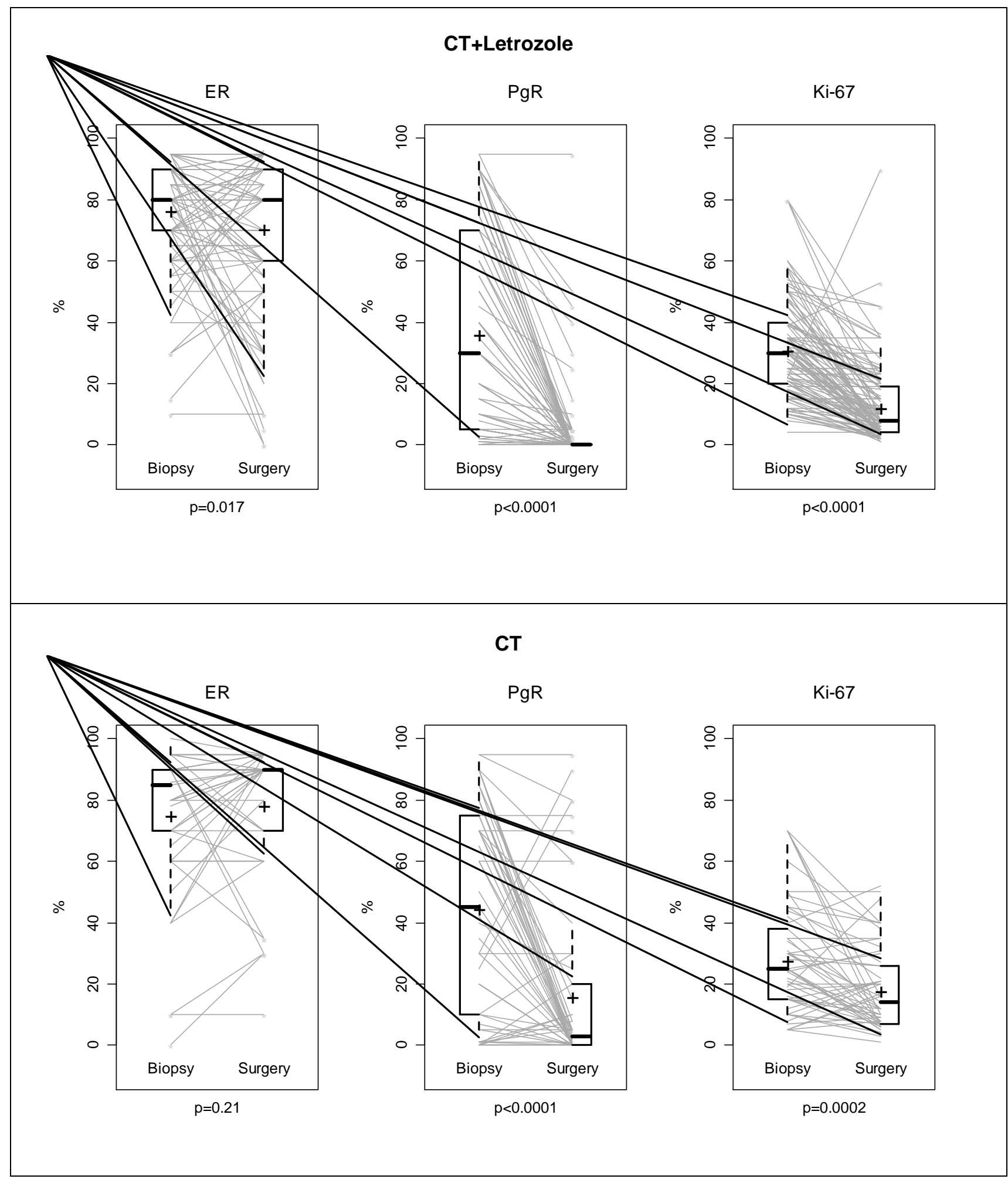

Abbreviations: $\mathrm{ER}=$ estrogen receptor; $\mathrm{PgR}=$ progesterone receptor. 
Figure 2. Disease Free Survival (DFS), by study group

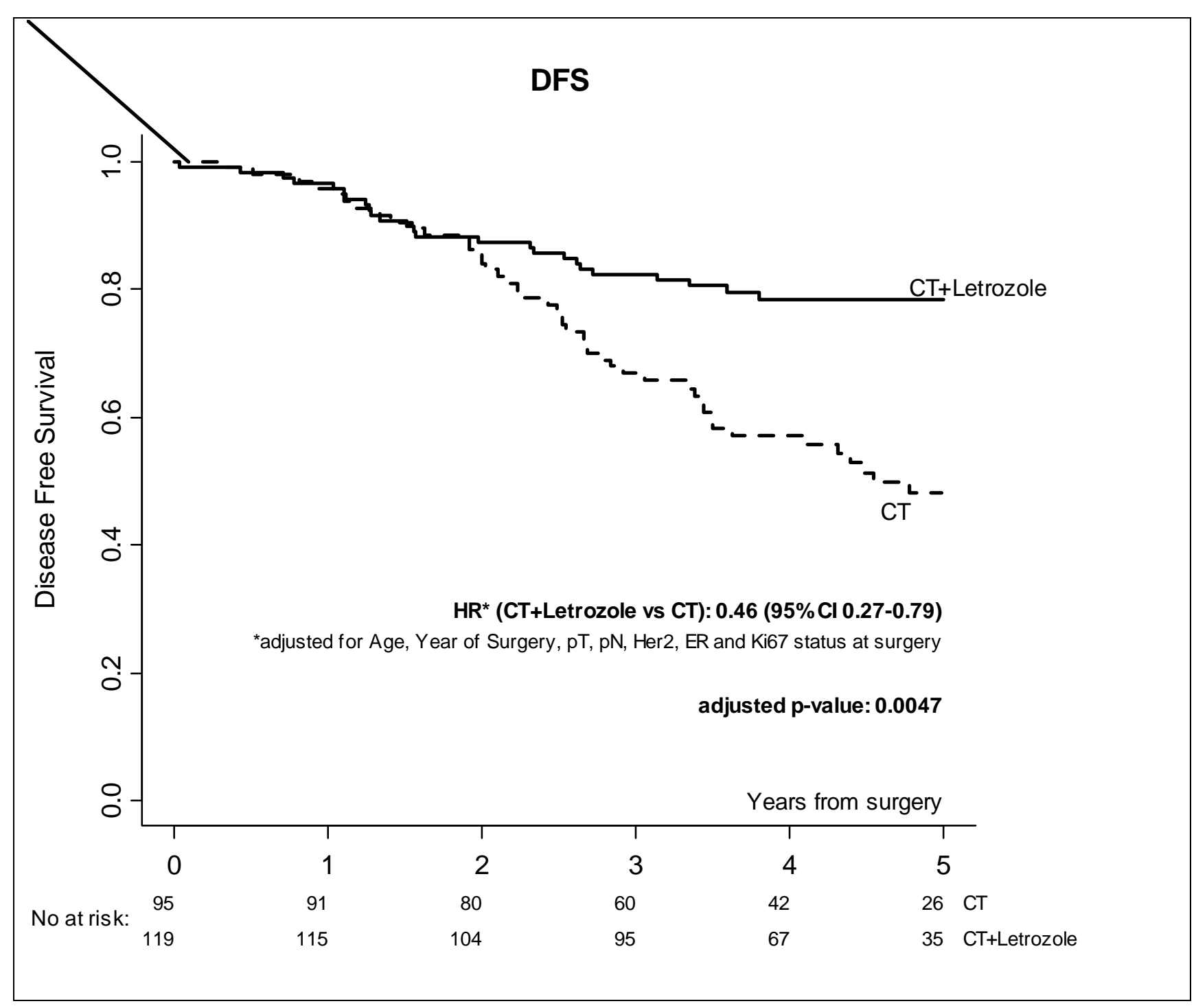


Figure 3. Time course of estradiol levels upon treatment with letrozole during primary therapy. Baseline refers to estradiol levels obtained after $\mathrm{GnRH}$ analog. Gray lines represent individual levels. Bold black line represents the median levels. The minimum detectable level is $5 \mathrm{pg} / \mathrm{ml}$.

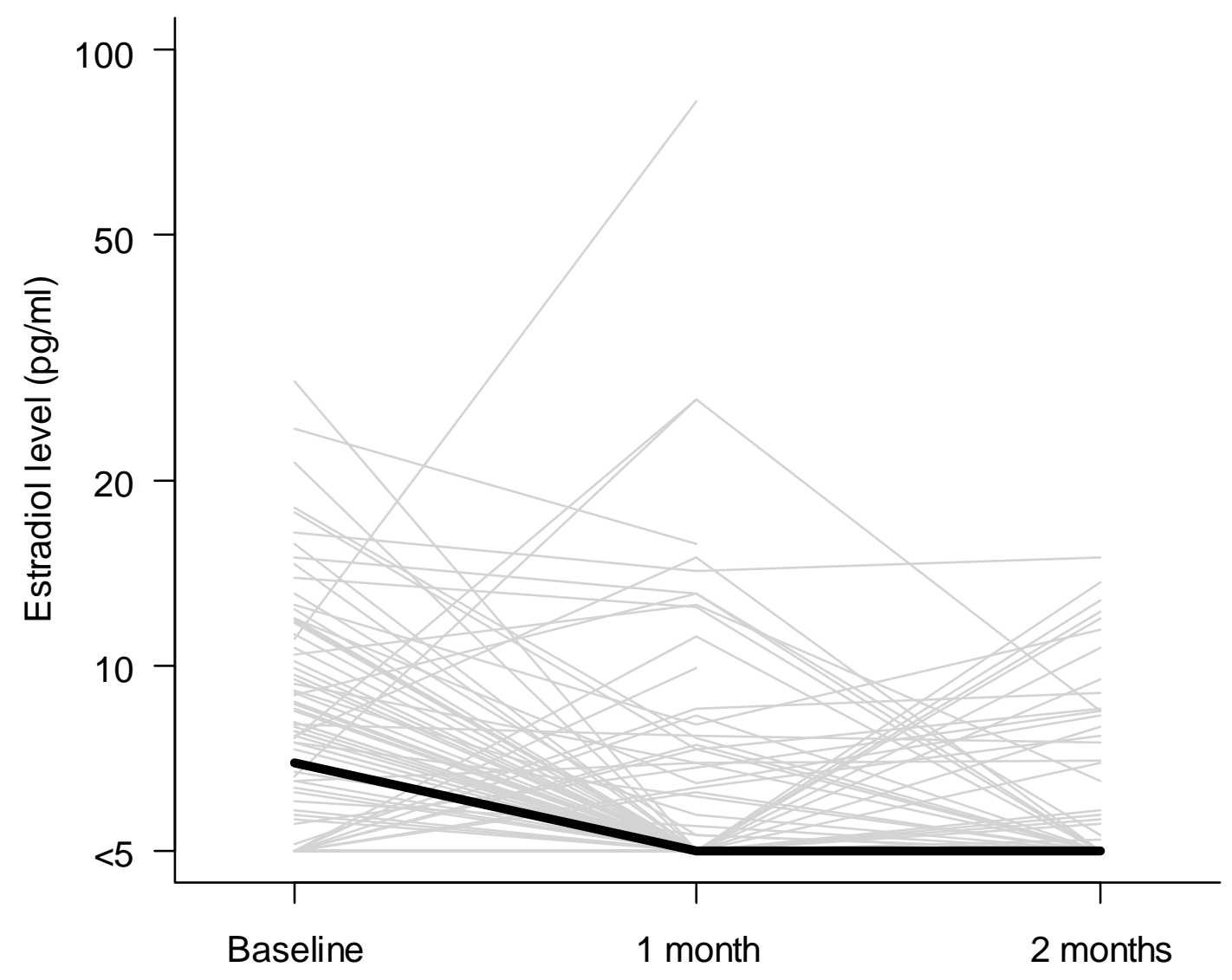


